Case Report

\title{
Guillain Barre Syndrome in a Young Man with SARSCoV-2: A Rare Association
}

\author{
Aashima Dabas', Naresh Kumar $^{2}$ \\ ${ }^{1}$ Associate Professor of Paediatrics, Maulana Azad Medical College, New Delhi, India. \\ ${ }^{2}$ Professor of Medicine \& Head, Pulmonary Medicine, Maulana Azad Medical College, New Delhi, India. \\ DOI: https://doi.org/10.24321/2349.7181.202104
}

\section{I $\quad \mathbf{N} \quad \mathbf{F} \quad \mathbf{O}$}

\section{Corresponding Author:}

Naresh Kumar, Pulmonary Medicine, Maulana

Azad Medical College, New Delhi, India.

E-mail Id:

drnareshmamc@gmail.com

Orcid Id:

https://orcid.org/0000-0003-4581-609X

How to cite this article:

Dabas A, Kumar N. Guillain Barre Syndrome in a Young Man with SARSCoV-2: A Rare Association.

J Adv Res Med. 2021;8(1):22-25.

Date of Submission: 2021-02-29

Date of Acceptance: 2021-03-22

\section{$\begin{array}{llllllll}\mathbf{A} & \mathbf{B} & \mathbf{S} & \mathbf{T} & \mathbf{R} & \mathbf{A} & \mathbf{C} & \mathbf{T}\end{array}$}

Guillain Barre Syndrome (GBS) is usually a post-infectious autoimmune disease that manifests as acute ascending flaccid paralysis. The disease is usually uncommon. However, recently it was reported in a few COVID-19 cases before complete resolution of COVID symptoms. An association between olfactory-gustatory disturbances and sensory abnormalities is frequently observed in GBS with COVID-19. The electrophysiological studies usually reveal a demyelinating pattern. Respiratory involvement, as part of respiratory muscle paralysis or COVID-19 pneumonia, is associated with poor recovery in affected patients. Here, we present a case of a young man, pre-morbid healthy, who presented with GBS with mild COVID-19 infection. He successfully recovered after treatment with Intravenous immunoglobulin IVIg.

Keywords: COVID-19, Guillain Barre Syndrome (GBS), AIDP, Paralysis, Steroids, IVIg

\section{Introduction}

Coronavirus disease (COVID-19), caused by severe acute respiratory syndrome coronavirus 2 (SARS-CoV-2) is typically associated with respiratory illness (mild to severe), anosmia and/ or non-specific systemic complaints. Neurological manifestations of this disease are less commonly reported than other manifestations. Headache, stroke, seizure, encephalitis, vertigo, and paresthesia have been reported earlier. However, Guillain Barre syndrome (GBS) has been reported only on an occasional basis. ${ }^{1}$

GBS is an autoimmune polyneuropathy caused by infectious agents like Campylobacter, Influenza virus, Epstein Barr virus and Zika virus. The incidence of GBS was higher when associated with a COVID-19 positive state as compared to a negative state, suggesting probable neurotropism of this virus. ${ }^{2,3}$ We present below a case of SARS-CoV-2 infection in a young male who developed GBS and was successfully managed with intravenous immunoglobulin (IVIg).

\section{Case Report}

A 28-year-old man was hospitalized with tingling sensations in both legs for seven days, weakness of legs for four days, and difficulty in phonation and swallowing for the last one day. The tingling sensation began on both legs and was perceived in the right arm for the last two days. The weakness in legs had an ascending progression with initial distal muscles weakness, marked by slipping of footwear, gradually progressing upwards to involve the proximal muscles of the legs. The weakness also increased in severity with the patient not being able to sit unsupported or lift himself up from the bed. He denied any weakness in the upper limbs at admission. Since last one day, he had also developed difficulty in phonation and swallowing with nasal regurgitation of liquids. He complained of pooling of secretions in his throat. However, there was no difficulty in sensation or voiding of urine. He was afebrile at admission but gave a history of undocumented low-grade fever for 
the last three-four weeks. He also reported dysgeusia for the last seven days, however, there was no cough, throat pain, anosmia or shortness of breath. There was no history of rash, diarrhoea, vomiting, or jaundice. He was tested positive for SARS Cov- 2 infection on $20^{\text {th }}$ day of symptoms as part of screening, when admitted to the hospital with the above neurological complaints, and was referred to our centre. He had a past history of fistula-in-ano which was treated conservatively two months back, and was healed at present. There was no underlying co-morbidity. He was a non-smoker and non-alcoholic and a student by profession.

At admission, he was conscious and oriented with a blood pressure of $138 / 88 \mathrm{mmHg}$, heart rate of $94 /$ minute, respiratory rate of $18 / \mathrm{min}$ without any use of accessory muscles and oxygen saturation on room air was $97 \%$. General physical examination was unremarkable. Central nervous system examination revealed normal sensorium and intact memory. He had absent gag reflex with a nasal twang in his voice and pooling of secretions in the oropharynx. Rest of the cranial nerves were normal on clinical testing. Motor system examination revealed decreased tone in bilateral lower limbs with loss of muscle power (3/5) in muscle groups at hip, knee, and ankle. There was no weakness in the upper limb muscles. There was no involvement of the respiratory muscles or diaphragm. Single breath count was 22. The deep tendon reflexes were absent in both upper and lower limbs with absent Babinski reflex. Sensory system examination was normal for touch, vibration, temperature and pressure. There were no cerebellar or meningeal signs. Rest of the systemic examination was unremarkable.

A provisional diagnosis of acute ascending flaccid paralysis with bulbar palsy was kept. Nerve conduction study was performed which revealed prolonged distal latency in bilateral common peroneal and right posterior tibial nerve, but normal distal latency in median and ulnar nerves. Compound Muscle Action Potential (CMAP) amplitude was normal in the left posterior tibial nerve with reduced conduction velocity. F-wave was absent in bilateral common peroneal and posterior tibial nerves but normal in ulnar and median nerves. H-reflex was absent bilaterally in lower limb nerves, suggestive of Acute Demyelinating Inflammatory Polyneuropathy (AIDP). The laboratory investigations after admission showed haemoglobin of $14.1 \mathrm{~g} / \mathrm{dL}$, total leucocyte count of $7800 / \mathrm{mm}^{3}\left(P_{31} L_{63} M_{3} E_{1}\right)$ with normal renal function tests. Serum sodium, potassium and calcium were $134 \mathrm{meq} / \mathrm{L}, 4.4 \mathrm{meq} / \mathrm{L}$, and $10.2 \mathrm{mg} / \mathrm{dL}$, respectively. Liver enzymes were mildly elevated with alanine transaminase of $57 \mathrm{IU} / \mathrm{L}$ and aspartate transaminase of $69 \mathrm{IU} / \mathrm{L}$.

The patient was kept nil per oral and started on tube feeds with frequent oral suctions. He had received one dose of injectable methylprednisolone $40 \mathrm{mg}$ one day prior to admission in this hospital in view of his COVID-19 positivity. IVIg was started as $2 \mathrm{gm} /$ day as a slow intravenous infusion. $\mathrm{He}$ also received supportive treatment for SARS-CoV-2 with antioxidants, tablet zinc, tablet ivermectin and subcutaneous low-dose heparin once a day. The lower limb weakness started to improve by the third day of IVIg infusion and he was able to stand by day 10 of hospitalization. The bulbar palsy recovered slowly and he was started on semisolid feeds on day 12 of hospitalization. His repeat RTPCR test for SARS-CoV-2 was negative on day 14 of hospitalization and he was discharged on the $20^{\text {th }}$ day of hospitalization. He didn't develop any respiratory complications during the hospital stay. At discharge, he had residual bulbar weakness with minimal residual motor weakness in both lower limbs (muscle power at hip 4/5 and 5/5 in rest of the muscle groups).

\section{Discussion}

GBS can be a consequence of molecular mimicry between antibodies against SARS-CoV-2 and gangliosides on the surface of peripheral nerves. There have been recent reports of association of these two clinical conditions. ${ }^{2-5}$ The resultant immune mediated demyelination or axonal damage results in the clinical symptoms characterized by ascending flaccid paralysis with areflexia.

Most patients with GBS developed neurological symptoms before the complete resolution of COVID-19 symptoms. The average interval between onset of symptoms of SARSCoV2 and associated GBS varied from 14-24 days. ${ }^{2,4}$ The index patient developed neurological symptoms in the late third week of illness. A recent parainfectious profile has been reported with SARS-CoV2 where symptoms of GBS presented at mean 8 days of COVID-19 symptoms raising doubts as to the true cause of respiratory failure between GBS and COVID-19. ${ }^{5,6}$ The antiganglioside antibodies were negative in majority of the affected patients suggesting a probable direct neuronopathic pathophysiology instead of a postinfectious autoimmune phenomenon in COVID-19 with GBS. ${ }^{5}$

The presence of sensory symptoms and paraparesis/ quadriparesis was commonly seen in affected patients, unlike autonomic symptoms. ${ }^{4}$ Majority of the patients had associated pneumonia and required assisted ventilation. ${ }^{2,4}$ An olfactory-gustatory disorder was commoner in GBS patients with COVID positive status, as also in the index case, than those with COVID-negative status. This is probably a result of olfactory nerve being directly exposed to the virus through nasal invasion. ${ }^{3}$ However, as compared to GBS with COVID-19 negative status, those who were COVID-19 positive were more likely to have involvement of all four limbs, lower muscle strength, and requirement of intensive care. $^{2}$ On the contrary, there was no difference in the clinical 
features or recovery in $47 \mathrm{GBS}$ cases with respect to their COVID-19 status reported during the pandemic in the UK, probably suggesting the role of host factors in determining the severity of autoimmune process. ${ }^{7}$ The index patient had associated dysgeusia but did not require ventilatory support for COVID-19 or GBS.

The diagnosis of GBS is supported by albuminocytological dissociation in cerebrospinal fluid or characteristic pattern on electrophysiological studies. The pattern on electrophysiological studies can help classify acute polyneuropathy as Acute Inflammatory Demyelinating Polyradiculoneuropathy (AIDP), Acute Motor Axonal Neuropathy (AMAN), or Acute Motor Sensory Axonal Neuropathy (AMSAN). ${ }^{8}$ The SARS-CoV-2 associated GBS type has been reported as the AIDP variant in majority with a few patients showing AMAN or mixed variant. ${ }^{2,4,9}$

Almost $70 \%$ recovery rate was reported in affected cases, though old age and underlying severe COVID-19 were associated with poor prognosis. ${ }^{4}$ IVIg was used successfully in the majority of cases with a few patients requiring plasmapheresis or steroids. IVIg was started promptly and recovery was good in the index patient. An association with influenza vaccine has been inconclusively documented earlier based on comparison of observed cases of GBS in vaccine recipients than earlier proportion. ${ }^{10}$ However, whether a similar risk would be seen with the COVID-19 vaccine, is yet to be ascertained.

To conclude, the above case represents a relatively less frequent neurological manifestation of COVID-19 in a young previously healthy male. His COVID-19 remained mild in severity and GBS promptly responded to IVIg therapy.

\section{Conflict of Interest: None}

\section{References}

1. Lltaf S, Fatima M, Salman S, Salam J, Abbas S. Frequency of Neurological Presentations of Coronavirus Disease in Patients Presenting to a Tertiary Care Hospital During the 2019 Coronavirus Disease Pandemic. Cureus. 2020 Aug;12(8):-e9846. DOI 10.7759/cureus. 9846.

2. Filosto M, Piccinelli SC, Gazzina S, Foresti C, Frigeni B, Servalli MC, Sessa M, Cosentino G, Marchioni E, Ravaglia S, Briani C, Castellani F, Zara G, Bianchi F, Del Carro U, Fazio R, Filippi M, Magni E, Natalini G, Palmerini F, Perotti AM, Bellomo A, Osio M, Scopelliti G, Carpo M, Rasera A, Squintani G, Doneddu PE, Bertasi V, Cotelli MS, Bertolasi L, Fabrizi GM, Ferrari S, Ranieri F, Caprioli F, Grappa E, Broglio L, De Maria G, Leggio U, Poli L, Rasulo F, Latronico N, Nobile-Orazio E, Padovani A, Uncini A. Guillain-Barré syndrome and COVID-19: an observational multicentre study from two Italian hotspot regions. J Neurol Neurosurg Psychiatry. 2020
Nov 6:jnnp-2020-324837. doi: 10.1136/jnnp-2020324837. Pubmed. PMID: 33158914; Pubmed Central PMCID: PMC7650204.

3. Fragiel $M$, Miró Ò, Llorens $P$, Jiménez $S$, Piñera $P$, Burillo G, Martín A, Martín-Sánchez FJ, García-Lamberechts EJ, Jacob J, Alquézar-Arbé $A$, Juárez $R$, Jiménez $B$, Del Rio R, Mateo Roca M, García AH, López Laguna N, Lopez Diez MP, Pedraza García J, Fernández de Simón Almela A, Lopez Diaz JJ, Eiroa Hernández P, Ruiz de Lobera N, Porta-Etessam J, Fernández Pérez C, Calvo E, González Del Castillo J; SIESTA (Spanish Investigators in Emergency Situations Team) network. Incidence, clinical, risk factors and outcomes of Guillain-Barré in Covid-19. Ann Neurol. 2021 Mar;89(3):598-603. doi: 10.1002/ana.25987. Pubmed. PMID: 33295021.

4. Abu-Rumeileh S, Abdelhak A, Foschi M, Tumani $H$, Otto M. Guillain-Barré syndrome spectrum associated with COVID-19: an up-to-date systematic review of 73 cases. J Neurol. 2021 Apr;268(4):1133-70. doi: 10.1007/ s00415-020-10124-x. Pubmed PMID: 32840686; Pubmed Central PMCID: PMC7445716.

5. Kajumba MM, Kolls BJ, Koltai DC, Kaddumukasa M, Kaddumukasa M, Laskowitz DT. COVID-19-Associated Guillain-Barre Syndrome: Atypical Para-infectious Profile, Symptom Overlap, and Increased Risk of Severe Neurological Complications. SN Compr Clin Med. 2020 Nov 21:1-13. doi: 10.1007/s42399-02000646-w. Pubmed PMID: 33251483; Pubmed Central PMCID: PMC7680081.

6. De Sanctis P, Doneddu PE, Viganò L, Selmi C, NobileOrazio E. Guillain-Barré syndrome associated with SARS-CoV-2 infection. A systematic review. Eur J Neurol. 2020 Nov;27(11):2361-70. doi: 10.1111/ene.14462. Pubmed, PMID: 32757404; Pubmed Central PMCID: PMC7436512.

7. Keddie S, Pakpoor J, Mousele C, Pipis M, Machado PM, Foster M, Record CJ, Keh RYS, Fehmi J, Paterson RW, Bharambe V, Clayton LM, Allen C, Price O, Wall J, KissCsenki A, Rathnasabapathi DP, Geraldes R, Yermakova T, King-Robson J, Zosmer M, Rajakulendran S, Sumaria S, Farmer SF, Nortley R, Marshall CR, Newman EJ, Nirmalananthan N, Kumar G, Pinto AA, Holt J, Lavin TM, Brennan KM, Zandi MS, Jayaseelan DL, Pritchard J, Hadden RDM, Manji H, Willison HJ, Rinaldi S, Carr AS, Lunn MP. Epidemiological and cohort study finds no association between COVID-19 and Guillain-Barré syndrome. Brain. 2021 Mar 3;144(2):682-93. doi: 10.1093/brain/awaa433. Pubmed PMID: 33313649.

8. Van den Berg B, Walgaard C, Drenthen J, Fokke C, Jacobs BC, van Doorn PA. Gullian Barre syndrome: Pathogenesis, diagnosis, treatment and prognosis. Nat Rev Neurol. 2014; Aug;10(8):469-82. 
9. Sriwastava S, Kataria S, Tandon M, Patel J, Patel R, Jowkar A, Daimee M, Bernitsas E, Jaiswal P, Lisak RP. Guillain Barré Syndrome and its variants as a manifestation of COVID-19: A systematic review of case reports and case series. J Neurol Sci. 2021 Jan 15;420:117263. doi10.1016/jns.2020.117263. Pubmed PMID: 33321326; Pubmed Central PMCID: PMC7725056.

10. Centres for Disease Control and Prevention (Internet). Gullian Barre syndrome and Vaccines. Available from: https://www.cdc.gov/vaccinesafety/concerns/guillainbarre-syndrome.html\#: :text=When\%20there\%20 has\%20been\%20an,the\%20flu\%20than\%20after\%20 vaccination. 